\title{
Maquegua (Maquewe) y sus habitantes en la Araucanía del siglo XVI: geopolítica y economía aurífera en los términos de la Ciudad Imperial de Chile
}

José Manuel Zavala Cepeda*

Francisco Javier Medianero Soto**

Mirentxu Zeballos San Miguel ${ }^{* * *}$

Fecha de recepción: 20 de marzo de 2020. Fecha de aceptación: 11 de julio de 2020

\section{Resumen}

Este artículo muestra el papel jugado por el territorio de Maquegua (Maquewe) y sus habitantes en el marco de la geopolítica y la economía aurífera implementadas por los conquistadores españoles en la Araucanía del siglo XVI, a partir del estudio de documentación relativa a encomiendas y conflictos armados complementada con un análisis geográfico del territorio. Se obtiene como resultado una caracterización y localización de dicha unidad socioterritorial y un análisis casuístico del funcionamiento de la sociedad de conquista española, en relación con la población originaria en un área específica.

Maquegua (Maquewe) and its inhabitants in the Araucanía of the 16th century: geopolitics and gold economy in the terms of the Imperial City of Chile

\footnotetext{
Abstract

This article shows the role that the territory of Maquegua (Maquewe) and its inhabitants played in the context of the geopolitics and the gold economy implemented by the Spanish conquerors in 16th century Araucanía by studying documentation on encomiendas and armed conflicts, complemented

* Doctor por la Universidad de la Sorbonne Nouvelle, académico del Departamento de Ciencias Históricas, Facultad de Filosofía y Humanidades, Universidad de Chile. Santiago de Chile, Chile. E-mail: josezavala@ uchile.cl

** Doctor por la Universidad de Málaga, académico del Departamento de Antropología, Facultad de Ciencias Sociales, Universidad Católica de Temuco. Santiago de Chile, Chile. E-mail: javiermedianero@gmail.com

**** Licenciada por la Universidad de Chile, ayudante de investigación, Departamento de Ciencias Históricas, Facultad de Filosofía y Humanidades, Universidad de Chile. Temuco, Chile. E-mail: mirentxu.zeballos@ug.uchile.cl.
}

Palabras clave

tasa de Maquegua economía Aurífera siglo XVI mapuche siglo XVI geopolítica Chile siglo XVI

Key words

Maquegua tax 16th century gold economy 16th century Mapuche 16th century geopolitics Chile 
1. Este artículo presenta resultados de investigación del Proyecto Fondecyt Regular $\mathrm{n}^{\circ}$ 1170551, Tras la ruta del oro: los habitantes de La Araucanía frente a la ocupación española del siglo XVI, recepción, adaptación y resistencia.

2. Entendemos por Araucanía o Ngülümapu -en mapudungun- el territorio mapuche donde los españoles fundaron durante en el siglo XVI las ciudades de Concepción, Angol, Cañete, Imperial, Villarrica, Valdivia, Osorno y, posteriormente, Chillán. Este territorio es mucho más amplio que la actual región administrativa de La Araucanía y se extendía aproximativa y variablemente, según las épocas, entre el río Itata y el lago Llanquihue.

3. AGI, Chile 5o, Tasa de Maquegua, 1572.

4. Del mapudungun maquewe: lugar de maquis (aristotelia chilensis). with a geoarchaeological analysis of the territory. The result is a geographical characterization and location of said socio-territorial unit and a casuistic analysis of the functioning of the Spanish conquest society in relation to the original population in a specific area.

\section{Introducción ${ }^{1}$}

Este trabajo se inscribe en un enfoque etnohistórico que destaca la complejidad de la realidad indígena durante la etapa inicial de la conquista española de la Araucanía o Ngülümapu. ${ }^{2}$ Se trata de una línea de investigación que ha venido construyéndose desde fines del último milenio y en la que han contribuido diversos autores, entre los cuales cabe mencionar a: Leonor Adán (2014); José Bengoa (2003); Guillaume Boccara (1998); Tom Dillehay (2007, 2014); Francis Goicovich (2004, 2006); Leonardo León (1986, 1988-1989); Jacob Sauer (2012); José Manuel Zavala y T. Dillehay (2010), y J. M. Zavala, T. Dillehay y Gertrudis Payàs (2013). En general, estos estudios combinan una pluralidad de datos -principalmente arqueológicos, históricos y lingüísticos- con el propósito de otorgar mayor protagonismo y ofrecer una visión más integral del actor indígena en el contexto de la conquista española del territorio mapuche.

En esa línea, este artículo indaga sobre los comportamientos y la organización sociopolítica de los habitantes del territorio de Maquegua (Maquewe, en mapudungun) en el marco de la puesta en marcha de la economía aurífera española y de su base de sustentación laboral: la encomienda. En la medida que lo posibilitan las fuentes documentales, se abordan también los datos arqueológicos y el reconocimiento in situ de los escenarios geográficos. En un artículo publicado recientemente (Zavala, Dillehay y Medianero, 2020a) aportamos un análisis sobre esta temática pero para el área de las cuencas de los ríos de Cautín/ Imperial, Toltén y Valdivia. En esta ocasión, nuestro análisis se centrará en la parte alta del territorio interfluvial de los ríos Cautín y Toltén, esto es la denominada "isla" o "provincia" de Maquehua.

Nuestra principal hipótesis (Zavala, Medianero y Dillehay, 2020b) propone que la conquista española de la Araucanía no podría haberse sustentado si no hubiera existido, en dicho territorio, una sociedad indígena organizada sociopolíticamente, y con una economía y demografía previas lo suficientemente complejas y robustas como para hacer viable dicho proyecto, cuestión que no ha sido destacada por la historiografía chilena.

Maquegua nos brinda la oportunidad de adicionar evidencias para contrastar esta hipótesis, ya que constituye uno de los pocos casos -sino el único- de un territorio mapuche de la Araucanía sobre el que tenemos información proveniente de una visita de tasación de tributo indígena del siglo $\mathrm{XVI}^{3}$ (Góngora, 1954-1955). Si bien se trata de un resumen y no de un relato de visitación in extenso, este documento proporciona información relevante respecto a las formas de tributación, los habitantes y la economía local.

Junto con lo anterior, Maquegua -territorio localizado en la actual comuna de Padre Las Casas- muestra una continuidad histórica excepcional y conserva, hasta nuestros días, su denominación en una variante toponímica más fidedigna al mapudungun: Maquehue. ${ }^{4}$ El hecho de poder ubicar con relativa exactitud el territorio indígena donde se implantó una encomienda en el siglo $\mathrm{XVI}$, nos permite adicionar al conocimiento proporcionado por las fuentes históricas un análisis geográfico que lo enriquece. 
La documentación histórica y el acercamiento in situ al territorio hacen posible un abordaje monográfico de este caso, permitiéndonos ilustrar de manera casuística el funcionamiento del sistema colonial español en la Araucanía del siglo XVI y la reacción indígena que generó. Dicho sistema operó sobre la base de una economía aurífera en la cual las encomiendas jugaron un papel fundamental como proveedoras de la mano de obra minera (Jara, 1987; Amunátegui, 1909; Inostroza, 2013; Méndez, 2012).

\section{La Ciudad Imperial y sus riquezas}

El estudio de la provincia ${ }^{5}$ maqueguana es inseparable del de la Ciudad Imperial, puesto que en el siglo XVI hacía parte de sus términos. ${ }^{6}$ Por ello, nuestro análisis parte abordando primeramente los antecedentes respecto de la Ciudad Imperial, entendida no solamente como emplazamiento urbano sino en cuanto totalidad jurisdiccional.

Sobre La Imperial del siglo XVI, además de todos los datos proporcionados por los principales cronistas tempranos (Valdivia, [1541-1552] 1929; Vivar, [1558] 1966); Góngora Marmolejo, [1575] 1862; Mariño de Lobera, [1595] 1865) y por historiadores generalistas (Encina y Castedo, [1874] 1965; Barros Arana, 1884; Villalobos, 1986); cabe resaltar el aporte pionero de Thayer Ojeda (1911: 765914); la síntesis de Gabriel Guarda (1978), los estudios de Iván Inostroza (2013, 2014); las aportaciones de Adán (2014) en torno a los tipos de asentamientos indígenas y la actual investigación doctoral de Carlos Cardoso (2019).

En 1551, el conquistador Pedro de Valdivia ([1541-1552] 1929: 221) fundó la Ciudad Imperial a cuatro leguas ${ }^{7}$ de la línea de costa de la época, ${ }^{8}$ en una meseta elevada de unos $40 \mathrm{~m}$. sobre el cauce del río Cautín, rebautizado Imperial en su curso inferior por los españoles. Su ubicación no fue fortuita y aunque no controlara visualmente gran parte de la cuenca de dicho río, su emplazamiento fue un punto estratégico de articulación de tres recursos fundamentales para el proyecto colonial español: el oro, las tierras fértiles y una población abundante.

Pedro de Valdivia, expresa con elocuencia su asombro ante el panorama del hermoso valle del río Cautín-Imperial cuando informa al emperador Carlos Quinto de su descubrimiento:

Lo que puedo decir con verdad de la bondad desta tierra es, que cuantos vasallos de V. M. están en ella y han visto la Nueva España, dicen ser mucha más cantidad de gente que la de allá: es toda un pueblo e una simentera y una mina de oro, y si las casas no se ponen unas sobre otras, no pueden caber en ella más de las que tiene; próspera de ganado como lo del Perú, con una lana que le arrastra por el suelo; abundosa de todos los mantenimientos que siembran los indios para su sustentación, así como maíz, papas, quinua, mare, ají y frísoles. La gente es crecida, doméstica y amigable y blanca y de lindos rostros, así hombres como mujeres, vestidos todos de lana a su modo, aunque los vestidos son algo groseros. Tienen muy gran temor a los caballos; aman en demasía los hijos e mujeres y las casas, las cuales tienen muy bien hechas y fuertes con grandes tablazones, y muchas muy grandes, y de a dos, cuatro y ocho puertas; tiénenlas llenas de todo género de comida y lana; tienen muchas y muy polidas vasijas de barro y madera; son grandísimos labradores y tan grandes bebedores; el derecho dellos está en las armas, y así las tienen todos en sus casas y muy a punto para se defender de sus vecinos y ofender al que menos puede; es de muy lindo temple la tierra y que se darán en ella todo
5. Podemos avanzar que Maquegua constituía lo que los españoles denominaron en la Araucanía "provincia” y que correspondía a una macrounidad socioterritorial que agrupaba varias unidades menores, los lebos (levo). Posteriormente, lo que denominaban "provincia" también será identificado por su nombre en mapudungun, castellanizado como aillaregua (ayllarewe) (Zavala y Dillehay, 2010: 433-450).

6. Recordemos que las ciudades coloniales ejercían jurisdicción sobre amplios territorios que eran definidos como sus "términos".

7. Cuatro leguas equivalen aproximadamente a $22 \mathrm{~km}$, si consideramos que una legua corresponde a $5,5 \mathrm{~km}$. en promedio. Dicho lo anterior, la legua era una medida caminera variable, que dependía de las circunstancias del camino y del medio de transporte.

8. Actualmente, la línea de costa se sitúa a 35,8 km. de Carahue, ciudad que ocupa el mismo emplazamiento de la antigua Ciudad Imperial. Hay que considerar que se han producido importantes variaciones en la línea de costa debido a los movimientos sísmicos de la región, en particular luego de los terremotos de 1575 y de 1960. 
9. Esto lo sabemos por los informes del terremoto de 1575 , los cuales señalaban como un efecto positivo del desastroso sismo el despeje de la barra de la desembocadura del Imperial (Palacios, 2016).

10. Cuestión que hemos podido apreciar directamente en el terreno el 27 de septiembre de 2019. género de plantas de España mejor que allá: esto es lo que hasta ahora hemos reconoscido desta gente (Valdivia, [1541-1552] 1929: 223-225).

Es innegable que el adelantado tenía interés en mostrar la importancia de lo descubierto, y aunque quizás exagerara un poco no era lo fundamental de su descripción una fantasía de su imaginación, de otro modo no se habría fundado allí una ciudad erigida prontamente en sede obispal -la única existente del río Maule al sur- ni tampoco habría sido considerada, como muchas veces lo fue, futura capital del reino.

Dicho lo anterior, cabe preguntarse por la razón que impulsó a los españoles a fundar La Imperial un tanto alejada de la costa, considerando que en esta época la relación marítima era vital para cualquier enclave colonizador. En respuesta a ello, se puede argumentar que junto a lo poco propicio que fue considerada la desembocadura del río Imperial para el establecimiento de un puerto, ${ }^{9}$ está el hecho de que las tierras aledañas al tramo inferior del río eran inundables y pantanosas, cuestión que se aprecia aún hoy en día, ${ }^{10}$ y con mayor razón en la época. A esto hay que agregar que el río Imperial es navegable y por lo tanto La Imperial pudo haber sido pensada como puerto fluvio-marítimo, además del hecho de que gran parte de la población nativa y de sus tierras cultivables se localizaban río arriba del lugar donde se fundó la ciudad.

Sin lugar a dudas, las afirmaciones de Pedro de Valdivia sobre la gran cantidad de población y de recursos agropecuarios nativos de la cuenca del río Cautín-Imperial no eran fábulas, ya ha dado pruebas de ello Iván Inostroza, por ejemplo, al comparar los valores de remates de diezmos para el periodo 1552-1558 entre Santiago, La Imperial y Valdivia, donde se aprecia que los de La Imperial son superiores a los de Valdivia y solo un poco inferiores a los de Santiago, distrito más antiguo y consolidado (Inostroza, 2013: 118). En 1570, el recuento poblacional del reino de Chile realizado por López de Velasco (Cardoso, 2019: 4) cifró en 9.000 los indios tributarios de La Imperial y en 4.500 los indios de guerra, lo que da un total de 13.500 indígenas para dicha ciudad, si se suman ambas categorías.

La cantidad de vecinos es otro dato importante, las informaciones tempranas establecen en 80 el número inicial de habitantes de la ciudad (Valdivia, [15411552] 1929: 247; Thayer Ojeda, 1911: 823-825). Para 1570, López de Velasco (Cardoso, 2019: 4) cifró en 170 la cantidad de vecinos de La Imperial, ocupando la tercera posición en cuanto a número de vecinos entre las nueve ciudades chilenas existentes en ese momento, detrás de Santiago -400 vecinos- y de Valdivia -170 vecinos. A partir de estos datos, Cardoso (2019: 4) estima en 680, por lo bajo, a los habitantes españoles de La Imperial considerando un mínimo de cuatro miembros por grupo familiar.

Obtener la calidad de vecino en una ciudad traía, generalmente por añadidura, recibir indígenas en encomienda, aunque no faltaran quienes se vieron inhibidos o despojados de esta recompensa por el gobernante en ejercicio -cuando este no los consideraba de su confianza o interés. Thayer Ojeda (1911: 825-827), revisando varios documentos de la época, logró identificar por sus nombres a doce encomenderos, entre los vecinos de La Imperial, para el periodo que va de 1552 a 1561. Pero quienes recibieron encomiendas fueron, sin duda, muchos más. Pedro de Villagra señala en su probanza de 1562 que fueron 55 los primeros vecinos de La Imperial y que todos ellos tocaron repartimientos de 1.000, 2.000 y 3.000 encomendados, habiéndole correspondido a él, supuestamente, más de 15.000 indígenas (Villagra, [1562] 1897: 23). 


\section{El oro de La Imperial}

Los españoles no se equivocaron en la elección de los sitios para la fundación de las ciudades "de Arriba", ${ }^{11}$ entre estas La Imperial, pues en todas ellas había abundancia de oro de placer, el cual es fácil de extraer.

Los estudios geológicos muestran la importancia -aún en la actualidad- de los placeres auríferos fluviales y paleofluviales del sur chileno (Ruiz, 1965; Flores, 1979; Portigliati et al., 1988; Greinier, 1991; Stange et al., [c.2012]). En efecto, aparte de Andacollo y Marga-Marga, en los nortinos valles transversales de Elqui y Aconcagua, dos relevantes áreas de antigua explotación minera inca (Millán, 2001: 31), el resto de este tipo de yacimientos se concentra más al sur, en la cordillera de la Costa-Nahuelbuta, entre Concepción y Valdivia, coincidiendo con un área de roca metamórfica que se inicia en Concepción y termina en Puerto Montt y el sector occidental de Chiloé (Ruiz, 1965: 256).

Greinier (1991: 44) distingue tres tipos de áreas auríferas en la cordillera de la Costa-Nahuelbuta: a) los placeres aluviales relativamente pobres de Pillimpillim y LleuLleu, en la cumbre de Nahuelbuta; b) los placeres de acumulación aluvial en mantos apegados a los flancos de valles estrechos desde Constitución (VII Región) hasta Los Muermos (X Región), pasando por los faldeos de Nahuelbuta; y c) los lavaderos fluviales de acumulación en terrazas y bancos de meandros de ríos que se encuentran a los pies de las dos cordilleras, en estos últimos se encontrarían las pepas de oro más grandes de Chile. Los lavaderos de oro que los españoles explotaron durante el siglo XVI en los "términos" de la Ciudad Imperial corresponden principalmente a esta última categoría: lavaderos fluviales de acumulación en terrazas y banco de meandros de ríos.

En general, las fuentes históricas hablan de los lavaderos de La Imperial sin precisar con exactitud dónde se localizan y nombran dos áreas principales de explotación: el río Damas y las lomas de Calcoimo y Relomo (Petit-Breuilh, 1997; Méndez, 2012: 89-90; Inostroza, 2013: 114).

En el caso del río Damas casi con seguridad las zonas de lavado se extendían en bordura del cauce, desde las proximidades de la Ciudad Imperial hasta posiblemente las quebradas y vertientes que descienden de las estribaciones del macizo de Nahuelbuta y arrastran el material aurífero de los filones expuestos. En nuestras campañas de terreno ${ }^{12}$-marzo 2018, enero y septiembre 2019- hemos prospectado el área norte y sur del núcleo urbano de la actual Carahue -antigua Imperial-, cauce arriba de los ríos Damas y Colico en una superficie aproximada de 6.500 has en un marco cartográfico cuyas coordenadas UTM del polígono resultante son: A: 5726732 Lat. S./ 655190 Long O.; B: 5727923 Lat. S./ 659327 Long. O.; C: 5713945 Lat. S./ 661187 Long. O. y, D: 5715261 Lat. S./ 665930 Long. O.

Para el caso de las lomas de Calcoimo y Relomo, la zona de explotación se situaría más distante de La Imperial y a mayor altura en la cordillera de Nahuelbuta. Según Diego de Rosales, quien escribió a mediados del siglo XVII pero con muy buenas fuentes, estos lavaderos se encontraban donde el río Repocura entra en el Imperial (Rosales, [1674] 1989: 400). La cuestión es saber si Rosales se estaba refiriendo a la convergencia del río Repocura con el Cholchol, o a la de este último con el Cautín -lugar donde nace el río Imperial. Durante una de las indagaciones en el terreno realizada en esta área (enero 2019) exploramos una superficie aproximada de 3.100 has, cuyo marco cartográfico tiene las
11. En la época, se llamaba "ciudades de Arriba" a las más meridionales del reino de Chile. Inicialmente, se incluía a Concepción pero en la medida que avanzó la conquista hacia tierras australes generalmente se tiende a señalar con esta denominación a las situadas al sur del río Biobío.

12. Metodológicamente, las campañas fueron de tipo prospectivas extensivas, con el objetivo de documentar, tentativamente, estructuras y presencia humana afín a una actividad aurífera; caso de diques de rebaje de energía fluvial, asentamientos tipo campamentos, arquitectura arqueológica logísti$\mathrm{ca}$, cultura material en superficie, etc., en marcos prospectivos de índole geo-arqueológico y donde el aporte de la disciplina geológica ha sido decisiva en nuestro quehacer de campo (Frutos, 1981; Portigliati, 1999; Pincheira et al., 1991). 
siguientes coordenadas UTM del polígono resultante: A: 5742599 Lat. S./ 674894 Long. O.; B: 5738077 Lat. S./ 686114 Long. O.; C: 5740037 Lat. S./ 974177 Long. O. y, D: 5735913 Lat. S./ 685128 Long O. En esta prospección de superficies no se encontraron evidencias directas de actividad, como por ejemplo indicios de cultura material o restos arquitectónicos; ni indirectas, como pudieran ser huellas o señales de fuerte actividad antrópica con cambios significativos en cursos de agua o en el paisaje.

Con todo, las áreas de explotación de placeres auríferos de La Imperial se deben haber extendido mucho más allá de los dos sectores antes descritos. En efecto, el registro moderno de placeres auríferos del Servicio Nacional de Geología y Minería (en adelante, SERNAGEOMIN) incluidos en el mapa "La Isla de Maquegua y los placeres auríferos de La Imperial" (Fig. 1) muestra una gran cantidad de yacimientos en el área cubierta por la antigua Ciudad Imperial, en total 219. Es verdad que dicho catastro no especifica si se trata de placeres de antigua o reciente explotación, pero su gran cantidad es indicativa de una zona altamente aurífera.

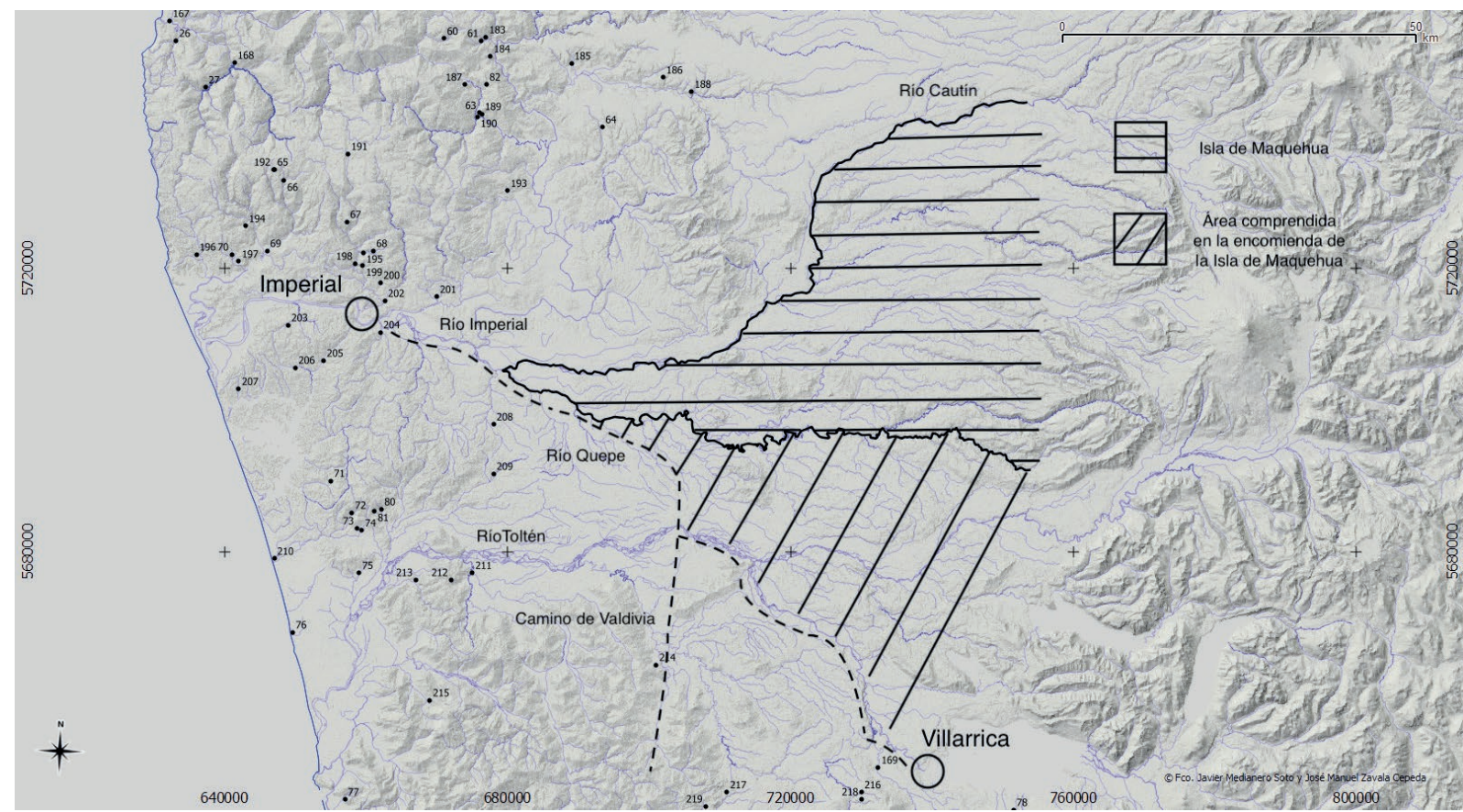

Placeres auríferos según SERNAGEOMIN: 26. Estero Quilquilco; 27: Río Loncotripai; 6o: Pichipellahuen; 61: Estero la Mina; 63: Estero Madihue; 64: Nilpe; 65: Los Embanques; 66: El Encanto; 68: Quebrada Lucero; 69: Trovolhue; 70: Puyanhue; 71: Estero Bolleco; 72: Estero Quilmer; 73: Estero Las Minas; 74: Agua Grande; 75: Toltén; 76: Porma; 77: Limahue; 78: El Molco; 80: Salamanca; 81: El Laurel; 82: Chupilco; 167: Quilquilco; 168: Río Tirua; 169: Nancul; 183: Pichipellahuen; 184: Rucatraro: 185: Estero Coihueco; 186: Afluentes río Quillén; 187: Estero Madihue; 188: Estero Quiloco; 189: Río Repocura; 190: Guamaqui; 191: Mitrauquén; 192: Estero Los Nochas; 193: Afluentes del estero Romolhue; 194: Estero La Muela; 195: Carahue; 196: Afluentes del río Punyahue; 197: Afluentes del río Moncul; 198: Río Cólico y estero Santa Celia; 199: Santa Celia; 200: Afluentes del río Cólico; 202: Río Couco y río Damas; 203: Estero Curilefu; 204: Estero Quillén y Curaco; 205: Afluentes del Pochilca; 206: Estero Curilefu; 207: Estero Millanitue; 208: Estero Arenas Blancas y Huichaue; 209: Estero Noqualhue; 210: Sedimentos de playa; 211: Río Mahuidanchi; 212: Afluentes del estero Couco; 213: Estero Llamuco; 215: Estero Pichiqueule; 216: Río Hiuscapi; 217: Afluentes del estero Challahuin o Niquen; 218: Estero Pichiluma y 219: Estero Quillén Alto.

Figura 1. La Isla de Maquegua y los placeres auríferos de La Imperial. Mapa elaborado por Francisco Javier Medianero y José Manuel Zavala.

Siendo los lavaderos un método de recuperación de partículas auríferas entre arenas fluviales su explotación requería que los lavadores se dispersaran y se desplazaran a lo largo de extensas áreas ribereñas, lo que dificultaba sin duda su control y otorgaba cierta autonomía a los trabajadores. No pasa lo mismo con una mina propiamente tal que tiende a la concentración geográfica de la actividad y, por lo tanto, facilita de cierto modo su control. 
La dificultad logística propia de la dispersión geográfica que provoca el lavado de arenas auríferas es un problema que se encuentra presente en el caso de La Imperial, particularmente en momentos de mayor conflictividad. Esto se evidencia, por ejemplo, hacia 1585 cuando el gobernador Alonso de Sotomayor afirmaba: "Las minas de La Imperial son muy ricas, pero no son minas de seguir sino lavaderos en quebradas y arroyos muy divididos, no se benefician por estar de guerra [...]" (Sotomayor, [c.1585] 1959: 229).

Unos seis años antes, en 1579, el teniente general Martín Ruiz de Gamboa en una carta dirigida al virrey del Perú manifestaba la importancia de los lavaderos de oro de La Imperial pero, al mismo tiempo, la dificultad de su explotación, decía:

E tratado con el governador mi señor dos cosas: lo primero que pues los vecinos de las cinco ciudades Imperial Ciudad Rica Baldivia Osorno Castro me davan de mil y trecientos indios amigos para arriba i estos forzosos se avían de ocupar en la guerra, los vecinos destas ciudades dichas diesen los quatro años dellos pa sacar oro en la Imperial y a gastos de guerra y fuese en la Imperial, donde se an descubierto muy rricas minas que ogaño con grande dificultad por las guerras que allá e tenido todavía sacaron más de sesenta myll pesos sin lo que los indios hurtaron y ansi mysmo en las otras ciudades se a sacado lo ordinario que con toda la guerra que e tenido siempre, con todo eso hize alto pa que en todas estas ciudades sacasen oro, que es El sustento de la tierra. La Imperial es el principio de la guerra principal i haciendo esto los vecinoshaga el governador mi señor hacer un fuerte y hacer alto sobre las minas, que en efecto son muy rricas y en muchas partes y desde allí haciendo este efecto salga capitán a hacer la guerra a las provincias de Purén Tucapel Arauco Mareguano y Coyuncos, por manera que del travajo bamos sacando fruto i que a esta riqueza vengan con sus quadrillas a sacar oro de todas las ciudades de arriba, demás desto ai otro Efecto bueno en esto que En hacer alto en estas minas hacen espaldas a lo de los indios alterados de las ciudades de arriba. ${ }^{13}$

Entre las propuestas que hacía Ruiz de Gamboa al virrey Toledo, cabe destacar la referente a que se permitiera a los soldados españoles beneficiarse del laboreo minero destinando las "piezas" capturadas -los cautivos de guerra- a dicha actividad y reservando algunos como soldados, señalaba:

Asimismo e tratado con el governador mi señor que mande que todos los soldados que anduvieren en el campo en la pacificacion de la tierra, todos los indios e indias que tomasen sean suios y tratar que las quadrillas todas que entraren en estas minas, porque los soldados hagan alto, sean obligados por cada cinquenta cavadores sustentar cinco u seis piezas de soldados para que en tomando los soldados algunas piezas pueda el governador mi señor mandar a fulano que los sustente y saquen oro pa El soldado. Todo esto esta vien a los vecinos, porque las minas son rricas y les será de mayor fructo y no haciéndolo cesaría El sacar oro y de esta manera El vien a todos, El governador mi señor le a parecido bien, espero En dios con esto i visto el provecho a de acudir mucha jente y an de andar contentos que de otra manera no ai fuerzas ni animo que les baste pa pasar el travajo i povreza grande que ai. Io prometo a Vuestra excelencia que es la tierra más rica y mejor que en todo lo que he visto ai y asi seria gran merced y favor el que este reino rreciviría. ${ }^{14}$

La petición de Ruiz de Gamboa era que no solo los señores encomenderos se beneficiaran de las explotaciones auríferas, en especial las de La Imperial, sino
13. AGI, Chile 31, Ruiz de Gamboa, 1 de abril de 1579 , f. 5 .

14. AGI, Chile 31, Ruiz de Gamboa, 1 de abril de 1579, f. 6. 
también los soldados y que no solo los indígenas encomendados trabajaban en ellas sino también los cautivos de guerra en calidad de esclavos.

Creemos que las citas anteriores manifiestan bien el gran valor que tuvieron los lavaderos de oro de La Imperial en el proyecto de conquista de la Araucanía pero muestran, al mismo tiempo, la gran resistencia que esto generó en sus habitantes y las enormes dificultades operativas con la que se encontraron los españoles.

\section{La Isla de Maquegua, un territorio estratégico en los términos de La Imperial}

La denominación de "isla", para ciertos espacios territoriales que no se encuentran circundados totalmente por cuerpos de agua, es corriente en el lenguaje colonial. En general se denomina "isla" en Chile colonial a territorios interfluviales relativamente altos que se encuentran divididos del territorio principal por un río y uno o varios de sus afluentes, formando una especie de triangulo cuyo vértice oriental imaginario lo constituye la cadena montañosa andina. Se trata, generalmente, de terrazas de acumulación aluvial ricas en limo y, por lo tanto, muy propicias para la agricultura. Es el caso, por ejemplo, de la Isla de La Laja conformada por el río Biobío y sus afluentes septentrionales, Laja y Claro, y de la Isla de Maquegua que estamos estudiando.

La Isla de Maquegua es frecuentemente nombrada en la documentación relativa a La Imperial del siglo XVI. Maquegua es una denominación castellanizada del topónimo mapuche Maquewe, que es permanentemente citado en los documentos coloniales y en los republicanos del siglo XIX. Corresponde a un distrito o provincia importante del territorio mapuche con gran protagonismo histórico, a tal punto que finalmente el topónimo se fijó en su versión más próxima al mapudungun, "Maquehue", y no "Maquegua", lo que no es muy frecuente ya que generalmente ha ocurrido lo contrario: la terminación we (hue) del mapudungun castellanizada como gua o hua.

Hasta donde sabemos, la Isla de Maquegua corresponde al triangulo territorial conformado por el río Cautín por el Norte, Quepe por el Sur y las estribaciones precordilleranas y/o cordilleranas andinas por el Este (Asta- Buruaga, 1867: 210; Risopatrón, 1924: 527). Este hinterland de La Imperial del siglo XVI se iniciaba a la altura de la actual ciudad Nueva Imperial, en la conjunción del río Imperial y el Quepe -actual sector Entre Ríos- y se abría en abanico hacia el oriente. Con todo, en el contexto de la dominación hispana del siglo XVI se asocia la Isla de Maquegua a un área mucho más extensa que la prolonga hacia el sur, hasta hacerla limitar con el río Toltén; como se puede apreciar en la representación cartográfica que hemos elaborado (Fig. 1). En efecto, cuando se hace referencia al repartimiento ${ }^{15}$ de la Isla de Maquegua se incluyen $l e v 0^{16}$ que a todas luces se situaban más allá del interfluvio maqueguano, como por ejemplo el denominado "asiento" de Angadeo. ${ }^{17}$ Por otra parte, el alto número de habitantes que muestran las fuentes tempranas para la isla ${ }^{18}$ permite pensar que tales cantidades de personas difícilmente se podrían limitar al interfluvio de los ríos Cautín y Quepe.

La documentación colonial temprana destaca la Isla de Maquegua como uno de los territorios más importantes de los términos de la Ciudad Imperial, verdadero soporte del proyecto colonizador de la Araucanía. Los extensos litigios judiciales por la propiedad de sus pobladores encomendados, y el 
hecho de que haya sido una de las pocas -sino la única- encomiendas del sur con evidencia documental de una tasación avalan esta afirmación.

La importancia de Maquegua, pero sobre todo el peso de su población, se aprecia, por ejemplo, en 1582 cuando el Consejo de Indias le reprochaba al ex-gobernador de Chile, Doctor Bravo de Saravia, el haber encomendado a su hijo, Ramiriáñez, dicho repartimiento: "[...] con el cual se podía pagar muchos conquistadores y soldados beneméritos y reformar la ciudad Imperial con solo este repartimiento, que se entiend] e que es el mejor de aquel reino [...]" (Consejo de Indias, [1582] 1957: 152).

El valor de Maquegua era la gran cantidad de población que la habitaba, pero también el hecho de que se localizara sobre la ruta que unía La Imperial con Villarrica y el puerto de Valdivia. Se trataba, pues, de un distrito muy poblado y con grandes recursos que deslindaba con el camino real que unía las tres ciudades; por lo tanto, más valía tenerlo bajo control y pacificado pues de lo contrario las consecuencias podían ser gravísimas para los establecimientos españoles.

La valía geopolítica de este espacio interfluvial parece anterior a la presencia española, de otro modo resulta difícil de explicar las complejas estructuras poliorcéticas ${ }^{19}$ y las tácticas militares que encontraron los conquistadores europeos allí.

Efectivamente, la resistencia activa que siguió en gran parte de la Araucanía a la derrota española que costó la vida al gobernador Pedro de Valdivia en Tucapel, a fines del año 1553, evidencia un sistema defensivo y organizativo particularmente desarrollado en esta provincia, a solo dos o tres años del primer contacto. La principal descripción de este sistema nace de la expedición que monta Pedro de Villagra hacia 1554 contra los sublevados que se habían refugiado en la Isla. Este episodio es relatado por los cronistas Vivar ([1558] 1966), Góngora Marmolejo ([1575]) 1862) y Mariño de Lobera ([1595] 1865) y se encuentra en la probanza presentada por Pedro de Villagra ([1562] 1897) y en los interrogatorios probatorios de la misma.

En la crónica de Vivar ([1558] 1966: 184-185 y 188) aparecen dos lugares con características poliorcéticas, Reinaco y Peltacavi; en la probanza de Pedro de Villagra ([1562] 1897: 28-29) también se mencionan dos fuertes, aunque solo se identifica y se dan detalles de Peltacavi; en Góngora Marmolejo ([1575] 1862: 178) y Mariño de Lobera ([1595] 1865: 177-178) solo se hace referencia a Peltacavi y no se menciona Reinaco.

Con todo, estos sitios fortificados se encontraban al interior de la Isla de Maquegua. En ello diferimos de la interpretación de Inostroza (2014: 7-8), quien los localiza -no sabemos porque razón- al norte del río Cautín, y la de Adán (2014: 304), quien ubica a Peltacavi en la costa, a diez leguas de La Imperial, quizás confundida por la designación de "puertos" de Peltacavi que le da Vivar. En efecto, la lógica de los sucesos ocurridos en el episodio relatado por Jerónimo de Vivar, así como las vías de comunicación y puntos defensivos españoles existentes en la época avalan nuestra convicción de que estos sitios formaban la denominada Isla de Maquegua. Tomás Guevara (1900: 129), generalmente bien informado sobre la historia y geografía del área, sitúa a Peltacavi en dicha isla. Por otra parte, las distancias señaladas para estos lugares: diez leguas de La Imperial para Peltacavi y doce para Reinaco (Vivar, [1558] 1966: 184-185 y 188) se corresponden bien con el sector alto de la Isla de Maquegua.
19. Las estructuras poliorcéticas representan entidades edilicias fuertemente muradas o construcciones con planimetrías que denotan un esfuerzo y trabajo humano cuya funcionalidad y resultado se enmarca en ingeniería militar (Mrakic, 2013; Palacios, 2019). 
20. Posiblemente haga referencia a una superficie rocosa muy lisa y resbaladiza.
Más allá de la localización específica de estos recintos fortificados, es muy interesante la descripción que da de ellos Vivar, porque señala que se trataba de emplazamientos que incluían conjuntos habitacionales en su interior. En el caso de Reinaco se trataría de una agrupación de habitaciones situada en la meseta de un cerro "alto" protegida, en parte, por una empalizada y, en parte, por una peña. Esta altiplanicie era de difícil acceso ya que por una vertiente había "grandes peñas", por otra era boscosa y por una tercera era un "terrazo" 20 peligroso de subir. La falda sur del cerro era circundada por un “pequeño río" (Vivar, [1558] 1966: 184).

Peltacavi también sería un recinto fortificado con espacios habitacionales, pero en este caso el elemento geomorfológico que se aprovechó defensivamente no es un cerro sino el piso de una cuenca. Según la descripción del cronista, se trata de un claro de bosque -un "grande y espeso monte", dice- circundado por un estero de lecho profundo. El recinto presentaría tres líneas defensivas; una primera de empalizada en la ribera misma del estero que protegía todo el largo del claro y no presentaba acceso; una segunda estacada, a buena distancia de la primera, con solo un acceso en uno de sus extremos; $y$, finalmente, una tercera línea del mismo material, esta vez con un acceso central protegido por otra empalizada que le servía de escudo. Al interior de la tercera línea se encontraban las viviendas en torno a una "gran plaza". El suelo del espacio situado en la primera y la segunda empalizadas presentaba socavones que dificultaban un asalto a caballo (Vivar, [1558] 1966: 188-189). Estos socavones, hechos a propósito, eran posiblemente fáciles de lograr por lo anegable del terreno pues en la probanza de Pedro de Villagra ([1562] 1897: 29) se les indica como "cavas de agua" y se agrega que Peltacavi estaba protegido por una ciénaga.

Ahora bien, este tipo de estructuras poliorcéticas mapuches parecen continuar existiendo en Maquegua más allá del primer decenio de conquista, pues en el memorial de servicios del capitán Francisco Hernández de Ortiz ([1589] 1963: 315), se señala que en tiempos del gobernador Sotomayor; es decir, entre 1583 y 1588 existía en las cabezadas de Maquegua el fuerte de Guerylauquén, donde se "recogían los indios" que estaban de guerra.

El interés que muestran los españoles durante todo el siglo XVI por Maquegua es la prueba de que este territorio y, sobre todo, sus habitantes constituían un recurso fundamental del proyecto colonizador del área sur de la Araucanía. En efecto, si consideramos que allí donde los españoles tenían interés y encontraban dificultades para controlar a la población establecían un puesto militar, Maquegua es un buen ejemplo de ello.

La presencia militar española en Maquegua fue temprana y duradera. Ya en 1554, se menciona la existencia de una guarnición hispana en la isla, ubicada a cuatro leguas de La Imperial (Villagra, [1562] 1897: 87). Para la década de 1580, en tiempos del gobernador Alonso de Sotomayor, se señala que el fuerte de la Isla de Maquegua se había mejorado, la antigua estructura de madera se había reemplazado por adobe y tapia (Hernández de Ortiz, [1589] 1963: 316). Durante el último decenio del siglo XVI, el fuerte de Maquegua se contaba entre los principales de la línea fortificada de la cuenca del río Cautín-Imperial; según el Padre Rosales ([1674] 1878: 285) su guarnición contaba con más de 600 indios amigos, y era el más cercano a la Cordillera de Los Andes, quedando de "espaldas" a Villarrica. En el estado del reino que manda establecer en 1594 el gobernador García Oñez de Loyola ([1594] 1960: 448) se señala que además de la guarnición de indios amigos, había en el fuerte de Maquegua españoles de "presidio". Un año antes, el 22 de noviembre de 1593, en el parlamento 
sostenido en La Imperial con representes de Maquegua, Oñez de Loyola instaba a los maqueguanos alzados a poblarse junto a dicho fuerte (Zavala et al., 2013: 242). Finalmente, para el gran levantamiento mapuche iniciado en 1598, el fuerte de Maquegua fue asaltado por los rebeldes (Álvarez de Toledo, 1862: 171).

Como podemos apreciar en las líneas anteriores, el fuerte de Maquegua fue un elemento destacado y permanente de la política de control territorial hispano del área sur de la Araucanía durante el siglo XVI, y contaba con una dotación importante de soldados indígenas y españoles.

\section{El codiciado repartimiento de la Isla Maquegua y su tasación}

La historia del repartimiento de la Isla de Maquegua se inicia con la fundación de la Ciudad Imperial en 1551. El primer beneficiario de esta encomienda fue Francisco de Villagra, compañero y brazo derecho de Pedro de Valdivia, primer gobernador de Chile. Villagra ([1558] 1900: 101) posee la encomienda hasta el año 1557, cuando asume el nuevo gobernador García Hurtado de Mendoza, lo somete a juicio y confisca todos sus bienes -entre ellos el repartimiento maqueguano.

En un registro de retiro de fondos de la Caja Real de Santiago del 28 de octubre de 1554, para hacer frente al alzamiento indígena, Francisco de Villagra deja como garantía de pago su encomienda $\mathrm{y}$, de paso, refiere la composición y localización de ella, dice:

[...] de los caciques é indios que el gobernador Pedro de Valdivia, difunto, de buena memoria, me dio y encomendó en nombre de Su Majestad en las dichas provincias de Arauco, los lebos é caciques y principales é indios dellos, siguientes: -Catenango, cacique del Lebo Aylangue y el cacique Clopallibanque; cacique del lebo Purumén y el cacique Qunilasan; cacique del lebo Puellocavi y el cacique Marinaval; cacique del lebo Alegueco, con todos los dichos cuatro lebos é con todo los caciques é principales indios, sus susjetos, que todos pueden ser cantidad de diez mill indios de visitación é tienen sus tierras é asiento en la isla que el dicho Gobernador á mí me dió y encomendó en nombre de su Majestad, que es en el río Cagtén (F. Villagra, [1554] 1900: 292, la cursiva es nuestra).

De la cita anterior, se desprende que Villagra se refiere a la Isla de Maquegua, cuya jurisdicción estaba dividida en cuatro levo: Aylangue, Purumén, Puellocavi y Alegueco. Cada levo contaba con un cacique principal, Catenango, Clopallibanque, Qunilasa y Marinaval y con otros caciques y principales sujetos a estos. En total, el autoproclamado gobernador estimaba en 10.000 los habitantes de la isla.

En 1563 Francisco de Villagra muere. Por una carta dirigida al Rey que escribe diez años después el deán de La Imperial, Agustín de Cisneros ([1573] 1957: 57-58), sabemos que fue su viuda -hermana del religioso-, doña Cándida de Montesa, quien retomó el control de la encomienda de Maquegua. La viuda fallece en octubre de 1572, lo que desata múltiples disputas por la propiedad de la encomienda maqueguana. En su carta, Cisneros solicitaba al Rey que dicho repartimiento fuera concedido por derecho sucesorio a Álvaro de Villagra, hijo de Francisco de Villagra e hijastro de Cándida de Montesa. Por la misma fecha, el obispo de La Imperial, fray Antonio de San Miguel ([1573] 
21. AGI, Chile 5o, Confirmación..., 1583.

22. AGl, Chile 50, 1572.
1957: 59-60), apoyaba igualmente la causa del hijo de Villagra en una misiva dirigida al Consejo de Indias. El obispo, al igual que su deán, desestimaba la pretensión del gobernador Bravo de Saravia de otorgar dicho repartimiento a su hijo Ramiríañez de Saravia.

En síntesis, a partir de 1572 dos bandos se enfrentan en las alegaciones sobre la propiedad de Maquegua: por un lado, las autoridades eclesiásticas de La Imperial que defienden el derecho sucesorio de los Villagra y, por otra, la nueva autoridad política del reino, Bravo de Saravia, que pretende atribuir a su hijo un repartimiento que consideraba vacante.

Los cargos imputados en el juicio de residencia a Bravo de Saravia (Consejo de Indias, [1582] 1957: 152) dejan traslucir el hecho de que los indígenas encomendados -en este caso los de Maquegua- constituían un preciado botín y una herramienta política usada por los gobernantes para acrecentar su poder y fortuna familiar. El caso es emblemático y muestra cómo, a través de los matrimonios concertados por la autoridad política, se hacían pasar las encomiendas de unas manos a otras. En efecto, gracias a los arreglos matrimoniales del cuestionado gobernador, Juan de Ocampo San Miguel recibió finalmente la encomienda de Maquegua; Saravia hijo la cedió recibiendo en compensación el repartimiento santiaguino de Diego García de Cáceres, a través del matrimonio con la hija mayor y sucesora de este, Isabel de Cáceres. Por su parte, Diego García de Cáceres es compensado con la encomienda que Juan de Ocampo -convertido igualmente en su yerno al aceptar el matrimonio con su segunda hija y no heredera- poseía en Cuyo (Consejo de Indias, [1582] 1957: 152).

La contienda por el repartimiento de Maquegua entablada por los personajes más influyentes de la época da cuenta de su importancia y su alta cotización. Sin embargo, para sus encomenderos posiblemente no era propicio destacar su valor ya que aquello podría significar rendir cuenta de un recaudo mayor de tributo indígena, o simplemente no seguir cobrando dicho impuesto en "servicio personal" -como era la práctica corriente en Chile. De ese modo, se puede entender que en la cédula de 1583, que confirma la encomienda para Ocampo, se lea que los indios de Maquegua eran tan pobres que no entregaban una renta superior a los mil pesos, con lo cual su encomendero no podía sustentarse acorde a su rango. ${ }^{21}$

Dicho lo anterior, Maquegua fue un repartimiento tan importante como para haber sido visitado y tasado por oficiales reales -a pesar de encontrarse en una región continuamente en guerra. De ese trámite surgió la Tasa de Maquegua, promulgada por la Real Audiencia de Concepción el 15 de noviembre de $1572 .^{22}$ Esta disposición tenía por objeto fijar los tributos que los maqueguanos debían pagar a su encomendera, en ese entonces, la viuda de Francisco de Villagra, doña Cándida de Montesa.

\section{La Tasa de Maquegua}

La Tasa de Maquegua constituye el único texto, hasta ahora conocido, de tasación líquida de alguna encomienda particular del reino de Chile. Un traslado original de este documento se conserva en el Archivo General de Indias, en la Audiencia de Chile, legajo 50, se trata de una copia incluida en el expediente de confirmación de encomienda de Juan de Ocampo de San Miguel de 1583. Comprendiendo la importancia de esta fuente, Mario Góngora (1954-1955: 
202-205) transcribió una buena parte y la publicó en sus Documentos inéditos sobre la encomienda en Chile.

Sabemos, por la misma tasación de 1572, que para su elaboración la encomienda fue previamente visitada por funcionarios reales, de acuerdo con la normativa vigente, con el fin de fijar los tributos indígenas correspondientes.

El registro tasador ${ }^{23}$ revela la existencia de 329 indígenas en edad de tributar, ${ }^{24}$ 314 en la Isla de Maquegua y levo asociados y 15 en el Asiento de Angadeo. El documento identifica 26 caciques que ejercen autoridad en 10 levo. El levo que cuenta con más caciques posee siete, Chapidicuyqui, y los que menos, solo uno, en este último caso estaban el "principal" de Angadeo, Nescague e Isla de Maquegua.

La tasa establece un tributo provisorio de cuatro pesos y medio de oro al año por cada indígena encomendado y tributario, suma sujeta a la variación del número de indígenas encomendados en edad de trabajar y, por tanto, de tributar.

Ahora bien, esta matrícula impositiva revela el establecimiento de tributos diferenciados entre la Isla de Maquegua y levo asociados y el Asiento de Angadeo de la manera siguiente:

Isla de Maquegua y demás levo:

- Oro: 973 pesos, entre todos los levo, por año.

- Ropa: 80 piezas, mitad de hombre y mitad de mujer, por año. La encomendera provee la lana. Se establecen las medidas de la ropa a fabricar.

- Trigo: 445 fanegas de trigo y 200 de cebada, más sembrarle trigo y cebada a la encomendera, si es sin arados se aumenta la cantidad de siembras. La encomendera provee semilla, arados y alimento.

- Miel: 3 botijas.

Asiento de Angadeo:

- Oro: 15 pesos por demora de un año.

- Trigo: 82,5 fanegas de trigo, más la siembra de 10 fanegas con arados. La encomendera provee semillas, arados y alimento para trabajadores.

- Cosas: 21 pesos y medio en oro o en objetos que los indios tuviesen y el encomendero necesitase, tasados por el corregidor de la ciudad.

Es de suponer, por las cargas impuestas, que el Asiento de Angadeo correspondía a un territorio destinado exclusivamente a las tareas mineras y agrícolas, mientras los demás levo se ocupaban también del tejido y confección de ropa actividad generalmente realizada por las mujeres, lo que deja entrever que no eran solamente los hombres en edad de trabajar quienes contribuían con su esfuerzo al pago de la carga impositiva sino igualmente otros miembros de sus grupos familiares.
23. AGI, Chile 50, 1572.

24. Hombres entre los 18 y 50 años, según la Tasa de Santillán de 1559 (Jara, 1961). 
25. AGl, Chile 50, Tasa de Maquegua, 1572, f. 7 .
La disposición tributaria también establecía obligaciones y penas para la encomendera en caso de no cumplimento. Por ejemplo, se le ordenaba tributar a tiempo y no exigir a los tributarios más de lo tasado, ni otros servicios personales. Entre las medidas punitivas, en caso de no cumplimento, se establecía que debía restituir a los indígenas lo sobre-exigido y pagar una multa fiscal del "cuatro tanto". No cumplir con sus obligaciones podía llevar a la encomendera a la privación de su encomienda y confiscación de la mitad de sus bienes. ${ }^{25}$

Finalmente, el documento planteaba la necesidad de informar a los indígenas sobre lo que debían tributar y recibir y la obligación para la encomendera de asegurar su evangelización.

En resumen, la Tasa de Maquegua da cuenta de la existencia de varias unidades socio-territoriales indígenas al interior del repartimiento. El documento identifica e individualiza 10 levo y sus respectivos líderes, a quienes se les asignan tareas y cargas impositivas diferenciadas. Estas unidades socio-territoriales nativas constituyen la base a partir de la cual se determina y organiza la encomienda. Como podemos observar en este caso, y como ya lo hemos planteado para el caso de Nahuelbuta (Zavala y Dillehay, 2010: 438), la relación de administración y dominio del encomendero sobre los encomendados se sustenta en unas estructuras sociopolíticas preexistentes: los levo.

\section{Levo y caciques de Maquegua, 1554-1593}

Si comparamos entre sí las diversas fuentes del siglo XVI podemos observar algunas continuidades y cambios a nivel demográfico y sociopolítico de Maquegua.

En primer lugar, respecto al volumen de su población, las cifras van desde 10.000 indios "de visitación", cantidad que refiere Francisco de Villagra ([1554] 1900: 229) en 1554, a 3.000 indios "bien pagados" que indica el licenciado Navia ([1574] 1957: 93) veinte años más tarde, en 1574. Sin embargo, la tasa de 1572 contabiliza en total solo 329 indios tributarios, es decir los hombres en condiciones de trabajar, entre 18 y 50 años según la legislación vigente en la época. Es probable que las cifras de Villagra (1554) y de Navia (1574) estén haciendo referencia a la población total de Maquegua y no solamente a aquellos destinados a las mitas, como lo hace la tasa de 1572.

Otro elemento que se desprende del estudio de esta documentación -como ya lo anunciamos más arriba- es que las encomiendas operan sobre la base de una organización sociopolítica preexistente, que se mantiene a lo largo de los casi 50 años que duró la dominación española de la Araucanía: los levo y las autoridades de estos, los caciques.

También, el caso maqueguano nos confirma la idea que, tal como expresáramos en un trabajo anterior, en el último decenio del siglo XVI la voz "levo" tiende a desaparecer y a ser reemplazada por el término "regua" (rewe) (Zavala y Dillehay, 2010: 439-440). En efecto, si la palabra levo es fundamental en los registros de Maquegua de 1554, 1572, 1576, desaparece y es reemplaza por la voz regua en 1593 -como se puede ver en la Tabla 1 que hemos elaborado al respecto.

Por otra parte, si observamos los nombres de los levo identificados entre 1554 y 1593 (Tabla 1), podemos apreciar que en seis de estos existe cierta continuidad 


\begin{tabular}{|c|c|c|c|c|}
\hline Año & Levo identificados & $\begin{array}{l}\mathrm{N}^{\circ} \text { de } \\
\text { Levo }\end{array}$ & Caciques identificados & $\begin{array}{c}\mathrm{N}^{\circ} \text { de } \\
\text { Caciques }\end{array}$ \\
\hline & Alegueco & 1 & Marinaval & 1 \\
\hline \multirow[t]{8}{*}{1554} & Aylangue & 1 & Catenango & 1 \\
\hline & Puellocavi & 1 & Qunilasan & 1 \\
\hline & Purumén & 1 & Clopallibanque & 1 \\
\hline & & 4 & TOTAL & 4 \\
\hline & Angadeo (el principal del Asiento de) & 1 & Payllaman & 1 \\
\hline & Ayllincu & 1 & Lleconyco, Millanana & 2 \\
\hline & Chapidicuyqui & 1 & $\begin{array}{l}\text { Quecheuque, Cincallo, Vinanande, Quieno, } \\
\text { Bana Muñanco, Cabuilevo, Quenolui }\end{array}$ & 7 \\
\hline & Cuyuncabi & 1 & Don Juan, Diego Juan & 2 \\
\hline \multirow[t]{8}{*}{1572} & Llaullaquin & 1 & Don Cristobal Diego, Alonso Ninynango, Taucura & 3 \\
\hline & Maquegua (isla de) & 1 & Don Antonio & 1 \\
\hline & Nescague & 1 & Catecalquin Denerquirque & 1 \\
\hline & Paylo Liguen y Guidelevo & 2 & $\begin{array}{l}\text { Paylelicam, Naynangueno, Ancabilque, } \\
\text { Llancalicam, Antalecayo }\end{array}$ & 5 \\
\hline & Pocoya & 1 & $\begin{array}{l}\text { Peuquana, Guayquillanga, Noquequello, } \\
\text { Pencachina, Turicheo }\end{array}$ & 5 \\
\hline & & 10 & TOTAL & 27 \\
\hline & Angadeo (el principal del Asiento de) & 1 & Paillanangue & 1 \\
\hline & Ayllingo & 1 & Leranico & 1 \\
\hline \multirow[t]{7}{*}{1576} & Chayitiau & 1 & Neucuchen & 1 \\
\hline & Cudilevo & 1 & Yanasgueno & 1 \\
\hline & Llavellauquen & 1 & Don Pedro, Catecalquin & 2 \\
\hline & Maquegua (isla de) & 1 & Rodrigo, Lanquill[-]ngo & 2 \\
\hline & Purume & 1 & [--]nelon & 1 \\
\hline & Vidquen & 1 & Toncolne[-]e & 1 \\
\hline & & 8 & TOTAL & 10 \\
\hline \multirow[t]{2}{*}{1593} & $\begin{array}{l}\text { Reguas (rewe) "alzadas": } \\
\text { Puello, Purume, Guanco, Pundacave } \\
\text { (o Pindacaue) }\end{array}$ & 4 & $\begin{array}{l}\text { Guanchupillan, Monculef, Guenchunere, } \\
\text { Aucananco (Ancananco) (caciques); Vilamanqui } \\
\text { (Vilcamanqui), Cauquenande, Cheongoala, } \\
\text { Guaquichenque (Guaquicheuque), Melirebue, } \\
\text { Manquitigay, Tarcomanqui (Tureomanqui) } \\
\text { (caciques principales) }\end{array}$ & 11 \\
\hline & & 4 & TOTAL & 11 \\
\hline
\end{tabular}

Fuentes: Villagra ([1554] 1900); AGI, Chile 50, Tasa de Maquegua, 1572 y Encomienda y posesión...,1576; AGl, Patronato 227; Zavala et al., (2013). Elaboración: José Manuel Zavala.

Tabla 1. Levo y caciques de la Isla de Maquegua, 1554-1593.

denominativa: es el caso del levo de Puellocavi de 1554 que parece convertirse en la regua de Puello en 1593 -si se le saca la sufijación cavi-; el de Purumén de 1554 es sin duda el Purume de 1576. Con menos distancia temporal, el levo principal de Angadeo se repite en los registros de 1572 y en 1576; al igual que el levo homónimo de la Isla Maquegua; lo mismo ocurre con Ayllencu -o Aylllango- y Llaullaquin -o Llavellauquen. 
26. En una publicación anterior (Zavala et al., 2013, 242) expresábamos la relación existente entre la categoría "asiento" y el lenguaje minero.
Angadeo, merece una mención especial porque, en primer lugar, se distingue de los otros levo -como ya hemos dicho- en términos de la contribución tributaria que se le exigía y, en segundo lugar, por su calificativo de "asiento", ${ }^{26}$ todo lo cual puede significar que fue en su propio territorio donde se llevaron a cabo faenas mineras sin necesidad de que los mitayos se desplazaran hacia lavaderos de oro más apartados.

Con relación a los sistemas de autoridad que deja traslucir esta documentación, cabe señalar el uso genérico del término de origen antillano "cacique" para designar a los líderes de los levo; bien que no todos figuraran situados al mismo nivel pues unos estarían "sujetos" a otros principales (Villagra, [1554] 1900: 292). En 1572, algunos de estos caciques son identificados con nombres cristianos: Don Juan, Diego Juan; Don Cristóbal Diego; Alonso Ninynago; Don Antonio. Esto revela que, al menos en teoría, habían cumplido con el rito católico del bautismo y, por lo tanto, se habrían convertido al cristianismo.

Por último, podemos hacer una observación respecto a la relación entre levo y caciques, apreciable en la tabla que hemos elaborado al respecto. De este modo, si en 1554 los cuatro levo identificados solo presentan un cacique cada uno; en 1572 de los diez levo que se registran, tres cuentan con un cacique; dos con dos; uno con tres; uno con cinco, dos juntos con cinco y uno con siete. En 1576 se cuentan ocho levo y el número de representantes por levo disminuye, pues seis parcialidades solo cuentan con un cacique y las dos restantes con otros dos. Finalmente, si para 1593 no es posible establecer qué caciques corresponden a qué regua (rewe), sí se registra un número superior de líderes por rewe pues se cuentan diez caciques para cuatro de estas unidades sociales. Lo anterior refuerza la idea de que los levo eran en sí unidades territoriales complejas, en cuyo interior se reconocían jerarquías o ámbitos de autoridad diferenciados.

\section{Conclusión}

Hemos podido apreciar en este trabajo el papel protagónico que jugó el espacio interfluvial denominado Isla de Maquegua en el desarrollo de la Ciudad Imperial del siglo XVI. Sus habitantes formaron parte del más importante repartimiento de la jurisdicción imperialina constituyéndose así en una de las principales fuentes de mano de obra de las faenas mineras, agrícolas e, incluso, textiles de la Araucanía.

En consecuencia, a pesar de la gran resistencia y rebeliones que la conquista española provocó en la Araucanía esto no impidió la incorporación -a lo menos durante ciertos periodos- de parte de su población al sistema productivo español a través de la encomienda. Si esto fue así, cabe preguntarse qué mecanismos políticos ayudaron a hacer efectiva dicha incorporación, teniendo en consideración la poca capacidad de control español sobre dicho territorio. Entre las respuestas a esta pregunta, está la puesta al servicio del nuevo modelo de estructuras jerárquicas y organizativas anteriores, como los levo, que permitían movilizar amplios conglomerados de población y poseían un sistema de autoridad con jerarquías e instancias deliberativas. Esto nos habla de estrategias políticas, de capacidad de liderazgo y de complejidad social indígenas que son anteriores a la presencia española.

La relevancia de la Isla de Maquegua también abarca un aspecto geopolítico. En efecto, su localización interior fue estratégica para las comunicaciones de la Ciudad Imperial con las de Villarrica y Valdivia, puesto que buena parte 
del camino entre estas ciudades recorría el vértice sur de este territorio. Por lo mismo, se trató de un camino con presencia de puntos fortificados que aseguraban a los españoles el tránsito de los pasajeros y mercancías pero, sobre todo, del oro de La Imperial que era quintado y exportado en el puerto de Valdivia (Zavala et al., 2020a).

Esta valorización geopolítica del interfluvio maqueguano es anterior a la presencia española, basta considerar el hecho que, desde el primer contacto con los europeos, sus habitantes contaban con complejas estructuras poliorcéticas que difícilmente podrían haber improvisado. La posición interfluvial de Maquegua facilitó, sin duda, su sistema defensivo al constituirse los ríos en barreras naturales. Lo anterior nos habla de conocimientos militares y defensivos prehispánicos, característicos de sociedades que habitaban territorios altamente codiciados por grupos que competían por su posesión.

En resumen, tanto a nivel socioeconómico como geopolítico la Isla de Maquegua ocupó un lugar destacado en el contexto colonial quinientista de la Araucanía, aspecto que tiene sus orígenes en un mundo prehispánico donde ya se destacaba por sus posibilidades agrícolas y defensivas. Estas características se vieron sin duda potenciadas por su ubicación central en la gran cuenca hidrográfica del Cautín-Imperial, rica en oro y en acceso a diversos recursos naturales.

\title{
Agradecimientos
}

Este artículo presenta resultados de investigación del Proyecto Fondecyt Regular $n^{\circ}$ 1170551, Tras la ruta del oro: los habitantes de La Araucanía frente a la ocupación española del siglo XVI, recepción, adaptación y resistencia, agradecemos a CONICYT-FONDECYT su financiamiento. Agradecemos especialmente a José Alfonso Llancamán, Cristian Obreque y Rodrigo Cabrera, grandes conocedores de la historia y del territorio de la comuna de Carahue -la Antigua Imperial. Del mismo modo, van nuestros agradecimientos a los evaluadores de este artículo cuyos comentarios lo han enriquecido.

\author{
Abreviaturas \\ Colección de Documentos Inéditos para la Historia de Chile (CDIHCh) \\ Colección de Historiadores de Chile ( $\mathrm{CHCh})$ \\ Servicio Nacional de Geología y Minería (SERNAGEOMIN)
}




\section{Duentes manuscritas}

\section{Archivo General de Indias (AGI), Sevilla}

"Audiencia de Chile (Chile):

Legajo 31: Carta de Ruiz de Gamboa del 1 de abril de 1579.

Legajo 50:

Tasa de Maquegua, Real Audiencia de Concepción, 15 de noviembre de 1572.

Encomienda y posesión de los indios de Maquegua, Santiago, 20 de agosto de 1576.

Confirmación de la encomienda de Maquegua a Juan de Ocampo, Consejo de Indias, Madrid, 21 de octubre de 1583.

»Patronato Real (Patronato):

Legajo 227: Requerimientos que hizo el Gobernador de Chile, Martín García de Loyola a ciertos indios, 22 de abril de 1594. 


\section{Q Bibliografía y fuentes publicadas}

" Adán, L. (2014). "Los reche-Mapuche a través de su sistema de asentamiento (S. XVXVII)". Tesis para optar al grado de Doctora en Historia, Universidad de Chile. (Ms.)

» Álvarez de Toledo, F. (1862). Purén indómito. Poema por el capitán Fernando Álvarez de Toledo. Leipizig, A. Frank'she Verlags/ Buchhandlung.

» Amunátegui, D. (1909). Las encomiendas de indígenas en Chile. Memoria histórica presentada a la universidad de Chile. Santiago de Chile, Impr. Cervantes. (2 v).

» Asta-Buruaga, F. (1867). Diccionario jeográfico de la República de Chile. Nueva York, D. Appleton.

»Barros Arana, D. (1884). Historia Jeneral de Chile t. 2, Santiago de Chile, Rafael Jover.

»Bengoa, J. (2003). Historia de los antiguos mapuches del sur. Santiago de Chile, Catalonia.

" Boccara, G. (1998). Guerre et ethnogenèse mapuche dans le Chili colonial: l'invention du soi. París, L’Harmattan.

" Cardoso, C. (2019). Recuento poblacional del sur del reino de Chile realizado por López de Velasco en 1570. Universidad de Sevilla, Informe de avance investigación doctoral. (Manuscrito facilitado por el autor).

"Cisneros, A. de ([1573] 1957). Carta al Rey de Agustín de Cisneros, deán de la Imperial, pidiendo mercedes para Álvaro de Villagra. Santiago, Fondo Histórico y Bibliográfico J.T. Medina, CDIHCh 2 (2): 57-59.

»Consejo de Indias (1957 [1582]). Ejecutoria del Consejo de indias sobre la residencia que tomó el licenciado Calderón al doctor Bravo de Saravia, presidente que fue de la Audiencia de Chile, 10 de marzo de 1582. Santiago: Fondo Histórico y Bibliográfico J.T. Medina, CDIHCh 2 (2): 137-156).

»Dillehay, T. (2007). Monuments, Empires, and Resistance: The Araucanian Polity and Ritual Narratives. Cambrige-New York, Cambridge University Press.

"Dillehay, T. (2014). The Telescopic Polity. Andean Patriarchy and Materiality. Suiza, Springer.

"Encina, F. y L. Castedo ([1874] 1965). Resumen de la historia de Chile. Santiago de Chile, Zig-Zag.

»Flores, R. (1979). Geología de los depósitos aluviales auríferos de la Cordillera de la CostaDécima Región. Segundo Congreso Geológico Chileno. Arica, 6 a 11 de agosto de 1979, sección C: 132-147.

» Frutos, J. (1981). Placeres auríferos IX y X regiones. Informe geológico preliminar sobre prospectos poco conocidos. Santiago de Chile, s/d. (Informe disponible en la Biblioteca del SERNAGEOMIN).

"Goicovich, F. (2004). Reevaluación etnohistórica de las Ayllareguas Reche-Mapuches. Actas V Congreso Chileno de Antropología I: 559-565. Santiago de Chile, Colegio de Antropólogos de Chile.

" Goicovich, F. (2006). Alianzas geoétnicas en la segunda rebelión general: génesis y dinámica de los vutanmapus en el alzamiento de 1598. Revista Historia 39: 93-154.

" Góngora, M. (1954-1955). Documentos inéditos sobre la encomienda en Chile. Revista Chilena de Historia y Geografía 123: 202-205.

" Góngora Marmolejo, A. ([1575] 1862). Historia de Chile desde su Descubrimiento hasta el año de 1575. Santiago, Imprenta del Ferrocarril, CHCh 2. 
" Greinier, G. (1991). Características y distribución de los placeres auríferos de Chile en Hérail, G. y M. Fornari (eds.), Simposio Gisements alluviaux d’or: 39-51. La Paz.

» Guarda, G. (1978). Historia Urbana del Reino de Chile. Santiago, Editorial Andrés Bello.

» Guevara, T. (1900). Historia de la civilización araucana. Anales de la Universidad de Chile 107: capítulo III, continuación.

» Hernández de Ortiz, F. ([1589] 1963). Memorial de los servicios que ha hecho en el reino de Chile el Capitán Francisco Hernández Ortiz. Santiago, Fondo Histórico y Bibliográfico J. T. Medina, CDIHCh 2 (6): 308-317.

"Inostroza, I. (2013). La colonización minera y agrícola en la ciudad Imperial del Sur de Chile: 1551-1561. Revista Complutense de Historia 39: 107-127.

»Inostroza, I. (2014). Las aldeas fortificadas mapuche y el tráfico minero indígena entre Araucanía y Neuquén, 1550-1560. Temuco, Universidad de la Frontera.

" Jara, Á. (1961). El salario de los indios y los sesmos del oro en la Tasa de Santillán. Santiago: Universidad de Chile, Centro de Investigaciones de Historia Americana.

» Jara, A. (1987). Trabajo y salario indígena a en el siglo XVI. Santiago de Chile, Editorial Universitaria.

» León, L. (1986). La resistencia anti-española y el rol de las fortalezas indígenas en Chile Central, 1536-1545. Sociedad, Hombre y Cultura (CUHSO) 3 (1): 53-116.

»León, L. (1988-1989). La alianza puelche-huilliche y las fortificaciones indígenas de Libén, Riñihue y Villarrica, 1552-1583. Nueva Historia 17: 13-46.

»Loyola, M. G. O. de ([1954] 1960). Testimonio del estado en que se hallaba el reino de Chile cuando entró el gobernador Martín García Oñez y Loyola y el que tiene al presente. Santiago, Fondo Histórico y Bibliográfico J.T. Medina, CDIHCh 2 (4): 442-452.

" Mariño de Lobera, P. ([1595] 1865). Crónica del reino de Chile, escrita por el Capitán Dn. Pedro Mariño de Lovera dirijida al Exmo. Señor Don García Hurtado de Mendoza, marques de Cañete, Vice-rei y Capitan Jeneral de los Reinos del Perú e Chile. Reducida a Nuevo Método, y Estilo por el padre Bartolomé de Escobar, de la Compañía de Jesús. Santiago, Imprenta del Ferrocarril, CHCh 6.

»Méndez, L. (2012). La minería en el sur de Chile en el siglo XVI en Quiroz, E. (coord.), Hacia una historia latinoamericana: homenaje a Álvaro Jara: 69-102. México, Instituto Mora.

» Millán, A. (2001). Historia de la minería del oro en Chile. Santiago, Editorial Universitaria.

" Mrakic, A. (2013). "El Desarrollo del Conocimiento Constructivo Militar Desde Vitruvio Hasta el Siglo XVII. Análisis de los Tratados de Arquitectura Militar". Tesis doctoral, Universitat Politécnica de Valéncia, España. (Ms.)

"Navia, L. ([1574] 1957). Carta del licenciado Navia, fiscal de la Real Audiencia, al Rey, 20 de enero de 1574. Santiago, Fondo Histórico y Bibliográfico J. T. Medina, CDHICh 2 (2): 91-102.

" Palacios, A. (2016). Fuentes para la Historia Sísmica de Chile (1570-1906). Santiago de Chile, Centro Diego Barros Arana/ DIBAM.

"Palacios, S. (2019). Cómo defender la frontera. Reflexiones sobre estrategias territoriales y poliorcética en el mundo hispano medieval. Intus - Legere Historia 13 (1): 3-36.

» Petit-Breuilh, M. (1997). Lavaderos de oro en la Araucanía: un enfoque históricogeográfico. Siglo XVI hasta principios del siglo XX. Actas del VIII Congreso Geológico Chileno 2: 1099- 1103. Antofagasta, Universidad Católica del Norte.

»Pincheira, M. Jaramillo, E. y N. Blanco (1991). Evaluación preliminar de los placeres auríferos de la VIII Región. Universidad de Concepción, para ENAMI, s/d. (Ms.) 
» Portigliati, C. (1999). Los placeres auríferos de Chile. Santiago de Chile, Servicio Nacional de Geología y Minería.

» Portigliati, C., Emparán, C y S. Vogel (1988). Los agentes geológicos en la formación de placeres auríferos en el sur de Chile. V Congreso Geológico Chileno: 393-418. Santiago de Chile, Universidad de Chile.

"Risopatrón, L. (1924). Diccionario jeográfico de Chile. Santiago, Imprenta Universitaria.

" Rosales, D. ([1674] 1878). Historia general de el reyno de Chile, Flandes indiano 2. Valparaíso, Imprenta del Mercurio.

" Rosales, D. ([1674] 1989). Historia general del reino de Chile: Flandes indiano 1. Santiago, Editorial Andrés Bello.

" Ruiz, C. (1965). Geología y yacimientos metalíferos de Chile. Santiago, Instituto de Investigaciones Geológicas Chile/ Editorial Universitaria.

"San Miguel, A. ([1573] 1957). Carta de fray Antonio de San Miguel al Consejo de Indias informando de las dificultades de la guerra y recomendando a varias personas. Santiago, Fondo Histórico y Bibliográfico J.T. Medina, CDIHCh 2 (2): 59-60.

"Sauer, J. (2012). Long-term resilience in cultural systems: An Araucanian example from Santa Sylvia, South-Central Chile. Tesis Doctoral, Universidad de Vanderbilt, Nashville, Tennessee, EE.UU. Disponible en Internet: https://etd.library.vanderbilt.edu//available/ etd-05202012-092727/unrestricted/SauerDissertation2012.pdf. Consultada el: 20 de junio de 2020.

"Sotomayor ([c.1585] 1959). Parecer de Alonso de Sotomayor sobre el beneficio de las minas de Chile. Santiago, Fondo Histórico y Bibliográfico J. T. Medina, CDIHCh 2 (3): 229-230.

"Stange, F., Collao, S. y S. Helle (s.f. [c.2012]). Posibles fuentes de los placeres auríferos en la Cordillera de la Costa, Región del Bio Bío, Chile. Concepción, Universidad de Concepción, Departamento de Ciencias de la Tierra.

» Thayer Ojeda, T. (1911). Las antiguas ciudades de Chile. Anales de la Universidad de Chile 129: 765-914.

»Valdivia, P. ([1541-1552] 1929). Cartas de Pedro de Valdivia que tratan del descubrimiento y conquista de Chile. Sevilla, Establecimiento Tipográfico de M. Carmona.

》Villagra, F. ([1554] 1900). Información rendida en Santiago por Francisco de Villagra, 6 de octubre de 1554 en Proceso de Francisco de Villagra. Santiago, Imprenta Elzeviriana, CDIHCh 1 (20): 280-298.

»Villagra, F. ([1558] 1900). Defensa de Villagra en Proceso de Francisco de Villagra. Santiago, Imprenta Elzeviriana, CDIHCh 1 (20): 95-103.

»Villagra, P. ([1562] 1897). Informaciones de los servicios de Pedro de Villagra, 11 de septiembre de 1562. Santiago, Imprenta Elzeviriana, CDIHCh 1 (13): 5-338.

"Villalobos, S. (1986). Historia del pueblo chileno T.III. Santiago de Chile, Instituto Chileno de Estudios Humanísticos.

"Vivar, J. ([1558] 1966). Crónica y relación copiosa y verdadera de los reynos de Chile hecha por Gerónimo de Bibar. Santiago de Chile, Fondo Histórico y Bibliográfico J. T. Medina.

»Zavala, J. y T. Dillehay (2010). El 'Estado de Arauco' frente a la conquista española: estructuración sociopolítica y ritual de los araucano-mapuches en los valles nahuelbutanos durante los siglos XVI y XVII. Chungara 42 (2): 433-450.

» Zavala, J., Dillehay, T. y G. Payàs (2013). El requerimiento de Martín García Óñez de Loyola a los indios de Quilacoya, Rere, Taruchina y Maquegua de 1593, testimonio oficial 
de parlamentos hispano-mapuches tempranos. Memoria Americana. Cuadernos de Etnohistoria 21 (2): 235-268.

»Zavala, J., Dillehay, T. y F. Medianero (2020a). Economía aurífera, caminos y fuertes en la Araucanía (Ngülümapu) del siglo XVI: en torno a la información de Martín Ruíz de Gamboa de 1579. Diálogo Andino 61: 27-39.

» Zavala, J., Medianero, F. y T. Dillehay (2020b). La actividad aurífera en el sur de Chile durante el siglo XVI: primeras aproximaciones arqueo-históricas en Lleras, R. y L. Vetter (eds.), Los Metales en nuestra historia. Lima, IFEA. (En prensa). 